\title{
Charcot, the Man, the Joint and its Care
}

\author{
Ahmad Al-Khattat ${ }^{1}$, Peter Gorman ${ }^{2}$, Winston Crasto ${ }^{3}$, Rajiv Nair ${ }^{4}$, Ponusamy Saravanan $^{5}$ and Vinod Patel ${ }^{6}$ \\ ${ }^{1}$ Clinical Doctor, $U K$ \\ ${ }^{2}$ Senior Lecturer in Wolverhampton University, UK \\ ${ }^{3}$ Clinical Director Medicine, UK \\ ${ }^{4}$ Consultant in Diabetes Care, UK \\ ${ }^{5}$ Professor of Diabetes, $U K$
}

*Corresponding author: Vinod Patel, Professor of Diabetes and Clinical Skills, Diabetes and Endocrinology Care Team, George Eliot Hospital NHS Trust, Nuneaton, England, UK.
Received Date: February 03, 2020

Published Date: February 21, 2020

\begin{abstract}
s
Charcot joint is a relatively painless destructive arthritis that may affect any joint in the body. Its pathophysiology was originally thought to be caused solely by sensory neuropathy, but other mechanisms have since been proposed. It can occur as a complication of a number of medical conditions, most commonly diabetes mellitus. Its significance lies in its potentially devastating effect on the affected joint and limb but more reassuringly, on the highly successful joint and limb preserving result of early recognition and management of this very important condition.

This article will briefly discuss some of the interesting history of Charcot joint, it's prevalence, aetiology, pathophysiology, diagnosis, prevention and treatment.
\end{abstract}

\section{Introduction}

The prevalence of diabetes mellitus has been exponentially increasing over the past few years and is expected to continue to do so over the coming decades. The international diabetes Federation [1] estimated the worldwide prevalence of diabetes at $8.3 \%$, with some 387 million people affected.

While acute diabetic complications, like diabetic ketoacidosis and hypoglycaemic attacks, can be prevented with simple manoeuvres and medically aborted within minutes to days, long term complications, like neuropathy and nephropathy, carry a lifelong insidiously progressive course with often poor end stage prognosis.

Diabetic Peripheral Sensory Neuropathy (DPSN) is one of the most important longterm complications of diabetes. Studies have estimated its prevalence in the diabetic population between 14$63 \%$ [2-8]. DPSN is the most common cause of Charcot joint in the western world $[9,10]$.

\section{Definition of charcot joint}

There are various definitions of Charcot joint; Rathur and Boulton [11], defines it as "... a non infective arthropathy in a wellperfused insensitive foot". Casado et al [12], on the other hand defines it as "... destructive arthropathy with severe bone resorption that occurs in patients with sensory neuropathy of any aetiology". Both definitions are emphasising the role of sensory loss and the vascular contribution to the pathogenesis of a Charcot joint reflecting current pathophysiological thinking.

\section{History}

While caring for patients with tertiary syphilis in 1868 in La Salpetriere Hospital, Paris, the French physician Jean-Martain Charcot described the condition, now known as "Charcot joint". In his original article [13] he described the grossly disorganised painless knee joints associated with late stages of syphilis as "Arthropathy of ataxic patients". That was not the only Charcot 
eponym (Figure 1). It was not until 1936 when Jordan described the same condition in people with DPSN.

\section{Eponyms:}

- $\quad$ Charcot Joint in tertiary syphilis

- $\quad$ Charcot-Marie-Tooth disease (Hereditary sensory-motor neuropathy)

- $\quad$ Charcot disease (Amyotrophic lateral sclerosis)

- $\quad$ Charcot-Wilbrand syndrome (Visual agnosia)

- Charcot intermittent hepatic fever

- $\quad$ Charcot tirade of acute cholangitis

- $\quad$ Charcot-Gombault necrosis (Biliary infarct)

- Charcot-Bouchard aneurysm (Small middle cerebral artery aneurysms)

- $\quad$ Charcot's triad of multiple sclerosis

Charcot-Leyden crystals (due to lysis of eosinophils) (Figure 1)

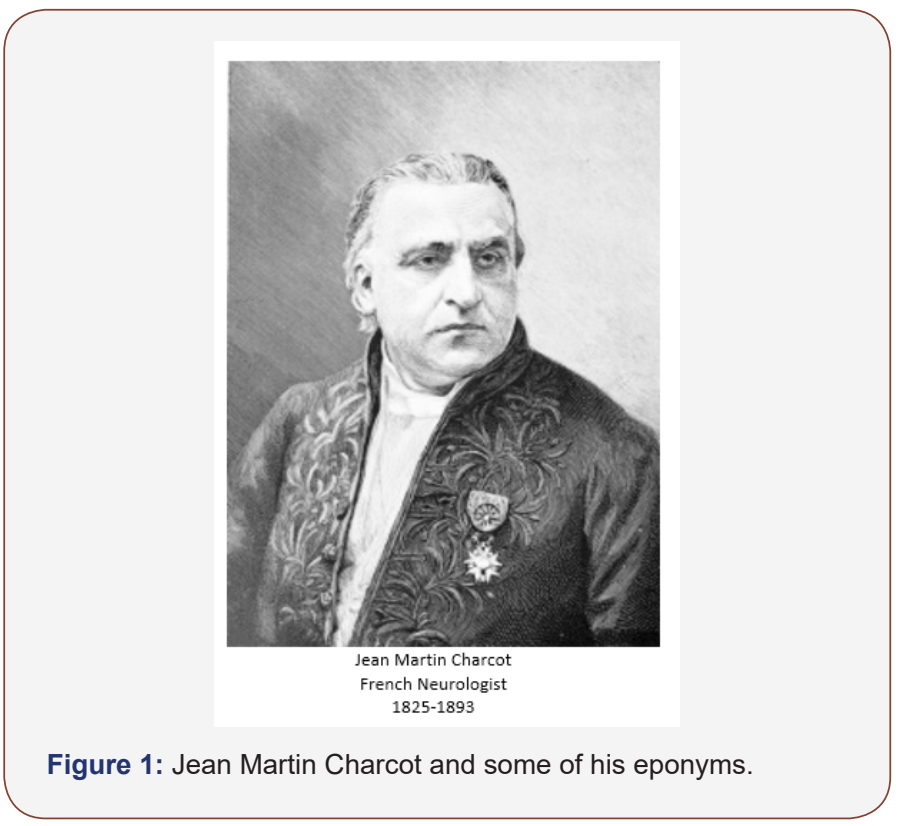

\section{Aetiology}

It is thought that Charcot joint can occur with any condition that may cause peripheral sensory neuropathy. Besides the aforementioned diabetes and neurosyphlis, Charcot arthropathy may also occur with Multiple sclerosis [14], Alcoholic neuropathy [15,16], HIV infection [17], Vitamin B12 and Folate deficiency, Syringomyelia, Leprosy, Meningomyeilocele and Poliomyelitis. Although all these conditions are associated with peripheral sensory neuropathy, DPSN is uniquely associated with markedly increased risk of lower limb amputation.

\section{Pathophysiology}

The exact pathophysiology of Charcot joint remains controversial and is likely to be multifactorial. There are, however, two theories that attempt to explain the pathophysiology of Charcot joint:

The neurotraumatic theory was the universally accepted theory for several decades [18] It proposes a vasa nervosum pathology that causes sensory disruption and loss of protective sensation and proprioception. This causes reduced perception of normally painful stimuli like stress, fatigue and repetitive trauma. Such repeated minor joint insult eventually results in severe damage to the affected joint.

The neurovasculartheory proposes disruption of the sympathetic autonomic vascular supply with hyperaemia. This causes increased osteoclast activity and bone resorption, fragmentation and eventually severs joint destruction and deformity [19].

\section{Clinical feature}

Although Charcot joint can affect any joint in the body, in people with diabetes, it most commonly affect one of the foot joints, usually tarsdometatarsal or midtarsal joint [20]. Suspicion of a Charcot joint must be one of the first on a differential diagnosis list in any person with diabetes who presents with a swollen, red, hot joint with or without pain and tenderness.

History of trauma may or may not be elicited and if the patient confesses to such history, it may be one of minor trauma that almost passed completely un-noticed. Owing to the mild or even absent pain, the patient may present at a later stage with established rocker bottom foot deformity (Figure 2 \& 3) with or without a plantar ulcer.

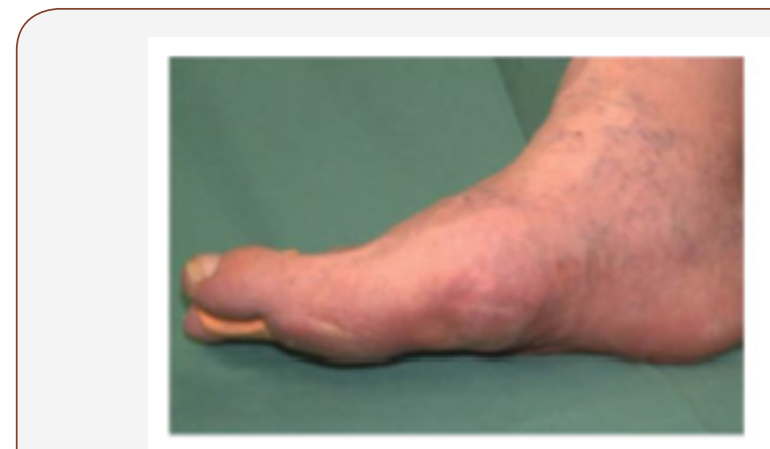

Figure 2: Rocker bottom foot.

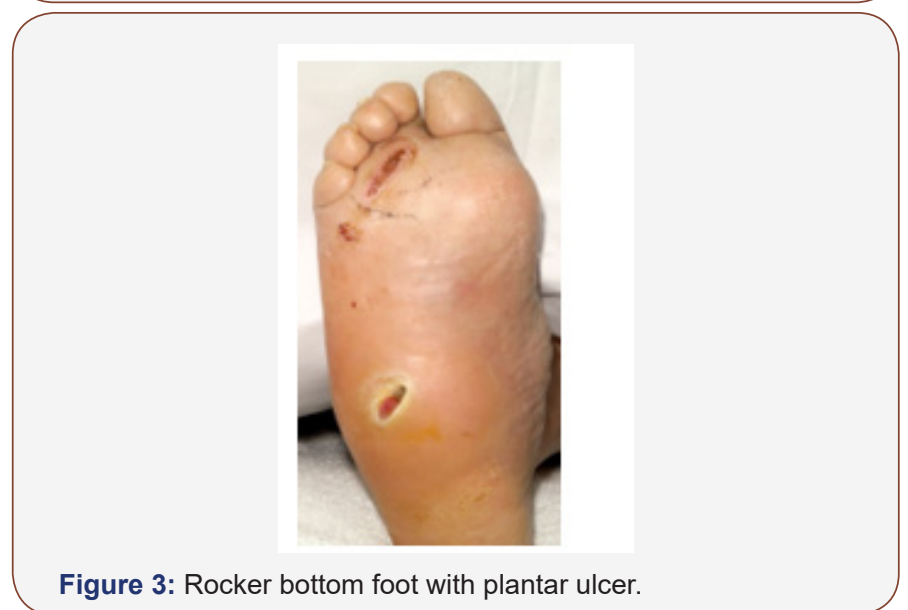


Features of neuropathic feet may include reduced vibration sensation perception, reduced 10 gram monofilament perception and impaired sharp-blunt discrimination. Examination may show clawing of the toes, prominent dorsal veins (Figure 4) and bounding pulses.

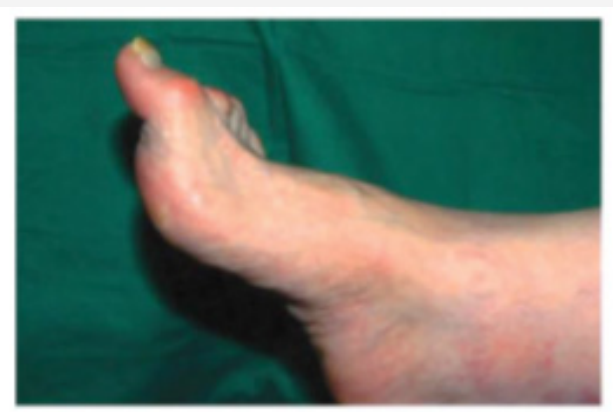

Figure 4: Neuropathic foot.

In a small number of cases it is difficult to distinguish between a deep foot infection and a Charcot arthropathy, especially if imaging yields inconclusive results, as often is the case, especially in the early stages of the disease.

\section{Diagnosis}

\section{Clinical}

Any swollen, worm, red foot in a diabetic is either a Charcot joint or a foot infection until proved otherwise (Box 1). The redness in a Charcot joint is usually more demarcated compared to the more advancing, hazy edges of redness caused by a foot infection. There may be a history of direct trauma to the affected joint or excessive activity, especially if this is unaccustomed. It remains however difficult to distinguish between these two conditions clinically in some cases. A previous history of a Charcot joint increases the risk of that joint for further episodes of reactivation of the Charcot process.

Box 1:

Box 2:

A swollen red hot foot in a diabetic is Early recognition and management a Charcot joint or a deep foot infec- of Charcot joint will preserve joint tion until proved otherwise. structure and function and markedly reduce the risk of lower limb amputation.

\section{Biochemical}

Although raised inflammatory markers may be seen with an active Charcot joint, this is non specific and only indicates the presence of an active inflammatory process. Some of these markers carry a prognostic significance.

\section{Radiological}

Plain x-rays of the affected joint are of low diagnostic sensitivity and are frequently normal, especially in the early stages [21]. Plain x-rays remain important however for documenting a base line of bone structure, alignment and density against which future radiographs can be compared [22]. MRI is now considered the test of choice in evaluating the complicated diabetic foot [23]. It will show Charcot arthropathy changes in the early stages, before such changes become visible on plain x-rays. Nuclear imaging may be highly sensitive for bone pathology but is not commonly used and positron emission tomography (PET) scanning is still under evaluation $[24,25]$.

\section{Treatment}

\section{Mechanical}

The most important immediate measure once a Charcot joint is suspected is offloading and immobilisation [26]. The ideal method to achieve this is complete non weight bearing but, this is both impractical and carries its own risks. A total contact cast is the current gold standard for achieving immobilisation and offloading. Other prefabricated devices like air casts (Figure 5) or other types of removable cast walkers may be used. Immobilisation and offloading will protect the foot joints against the development of severe joint deformity (Figure 5).

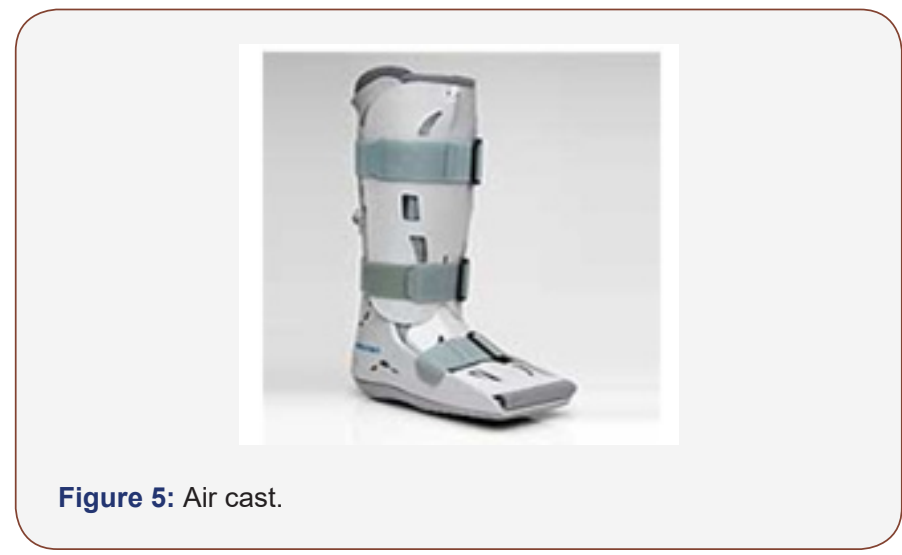

\section{Pharmacological}

Some small studies showed some benefit from using Bisphosphonates (Pamedronate, Alendronate) in the treatment of active Charcot joint $[27,28]$. A later larger UK population study showed no such benefit [29]. Some authors advocate intranasal calcitonin spray [30], while others advocate the use of potent anti-inflammatories, such as TNF-alpha inhibitors [31]. These treatments are yet to be backed by a robust evidence base.

\section{Surgical}

The International Task Force on the Charcot Foot convened in 2011 and recommended that surgical treatment of the Charcot foot should be reserved for cases of severe joint instability, infection, inability to immobilise and offload, or nonhealing ulcer $[22,32]$. Since the outcome of conservative treatment of Charcot of the ankle joint is usually poor, the panel recommended surgical intervention as the primary treatment for Charcot of the ankle joint. Complications of surgical treatment of Charcot joint are common and these should be addressed as they emerge [33]. 


\section{Conclusion}

Patient and professional education together with early recognition and treatment of Charcot joint will, without a doubt, preserve the affected limb and/or joint in almost all cases (Box 2). Lack of knowledge and late interventions, on the other hand, will almost certainly lead to severe irreversible deformity and loss of normal function of the affected joint with markedly increased risk of loss of limb. A worm swollen red foot in a diabetic must be immediately referred to specialist diabetic foot services for early management of Charcot joint and/or foot infection. Failure to do so may lead to severe foot joint deformity or spread of infection with osteomyelitis with markedly increased risk of lower limb amputation.

\section{Acknowledgement}

None.

\section{Conflict of Interest}

No conflict of interest.

\section{References}

1. International Diabetes Federation (2019) IDF Diabetes Atlas, Brussels, Belgium: International Diabetes Federation.

2. Boulton AJM, Malik RA, Arezzo JC, Sosenko JM (2004) Diabetic somatic neuropathies: Technical review. Diabetes Care 27: 1458-1486.

3. Yound MJ, Boulton AJM, Macleod AF, Williams DR, Sonksen PH (1993) A multicentre study of the prevalence of diabetic peripheral neuropathy in trhe unitedkingdom hospital clinic population. Diabetologia 36(2): 150-154.

4. Kumar S, Ashe H, Parnell LN, Fernando DJ, Tsigos C, et al. (1994) The prevalence of foot ulceration and its correlates in type 3 diabetes. Diabet Med 11: 480-484.

5. Cabesas-Cerrato J (1998) The prevalence of diabetic neuropathy in Spain: A study in primary care and hospital clinic groups. Diabetologia 41: $1263-1269$.

6. Abbott CA, Carrington AL, Ashe H, Bath S, Every LC, et al. (2002) The North West diabetic foot care study: incidence of, and risk factors for new diabetic foot ulceration in a community-cased patient cohort. Diabet Med 19: 377-384.

7. Walters DP, Gatling W, Mulee MA, Hill RD (1992) The prevalence of diabetic distal sensory neuropathy in an English community. Diabet Med 9: 349-353.

8. Dyck PJ, Kratz KM, Karnes JL, Litchy WJ, Klein R, et al. (1993) The prevalence by staged severity of various types of diabetic neuropathy, retinopathy and nephropathy in a population-based cohort: the Rochester Diabetic Neuropathy study. Neurology 43: 817-824.

9. Brodsky JW (2007) The diabetic foot. In: Coughlin MJ, Mann FA, Saltzman CL, (eds.), Surgery of ther foot and ankle. Philadelphia: Mosby Elsevier: 1333.

10. Shibuya N, LaFontaine J, Frania SJ (2008) Alcohol-induced neuropathy in the foot: A case series and review of the literature. J Foot Ankle Surg 47(2): 118-124.

11. Rathur HM, Boulton AJM (2005) Recent advances in the diagnosis and management of diabetic neuropathy. The Bone and Joint Journa; 87(12): 1605-1610.

12. Casado E, Arévalo M, Gliménez O, Orellana C (2014) Charcot arthropathy: A diagnostic challenge in diabetic patients. Clinical features in 21 cases. Ann Rheum Dis 73: Suppl 2.
13. Charcot JM (1868) Sur quelques arthropathies qui parnessent dépendre a'une lésiondu cerveauou de la moëlle épinière. Archives Physicle Normal Pathologie; 1: 161-78.

14. Bjorkengren AG, Weisman M, Pathria MN et al. (1988) Neuropathy associated with chronic alcoholism. American Journal Roentgenology 151(4): 743-745.

15. Diamond I, Messing RO (1994) Neurologic effects of alcoholism. Western Journal of Medicine 16(3): 279-287.

16. Morse RM, Flavin DK (1992) The definition of alcoholism. JAMA 268(8): 1012-1014.

17. Young N, Neiderer K, Martim B, Jolley D, Dancho JF (2012) HIV neuropathy induced Charcot neuroarthropathy: A case discussion. Foot 22 (3): 112-116.

18. Caputo G, Ulbrect J, Cavanagh P, Juliano P (1998) The Charcot foot in diabetes: Six key points. American Family Physician 57 (11): 2705-10.

19. Robinson AH, Pasapula C, Brodsky J (2009) Surgical aspects of the diabetic foot. J Bone Joint Surg Br 91(1): 1-7.

20. Obolensky L, Trimble K (2010) Importance of close surveillance for Charcot arthropathy in diabetic patients presenting to the emergency department with low-energy foot injuries. Emergency Medicine Journal 27: 484-485.

21. Morrison WB, Ledermann HP (2002) Work-up of the diabetic foot. Radiol Clin North Am 40: 1171-1192.

22. Rogers LC, Frykberg RG, Armstrong DG, Andrew JM Boulton, Michael Edmonds, et al. (2011) The Charcot foot in diabetes. Diabetes Care 34(9): 2123-2129.

23. Morrison WB, Ledermann HP, Schweitzer ME (2001) MR imaging of the diabetic foot. Magn Reson Imaging Clin N Am 9: 603-613.

24. Keidar Z, Militianu D, Melamed E, Bar-Shalom R, Israel 0 (2005) The diabetic foot: initial experience with 18F-FDG PET/CT. J Nucl Med 46: 444-449.

25. Hopfiner S, KrolaK C, Kessler S, Tiling R (2005) Preoperative imaging of Charcot neuroarthropathy. Does the additional application of 18F-FDGPET make sense? Nuklearmedizin 45: 15-20.

26. Fryberg RG, Mendezzoon E (2000) Management of the diabetic Charcot foot. Diabetes Metab Res Rev 16(Supp 1): S59-65.

27. Jude EB, Selby PL, Bugess J, Lilleystone P, Mawer EB, et al. (2001) Bisphosphonates in the treatment of Charcot neuroarthropathy: a double-blind randomised controlled trial. Diabetologia 44 (11): 20232037.

28. Pitocco D, Ruotolo V, Caputo S, Mancini L, Collina CM, et al. (2005) Siixmonth treatment with alendronate in acute Charcot neuroarthropathy: a randomised controlled trial. Diabetes care 28(5): 1214-1215.

29. Game FL, Catlow R, Jones GR, Edmonds ME, Jude EB, et al. (2012) Audit of acute Charcot's disease in the UK: the CDUK study. Diabetologia 55(1): 32-35.

30. Bem R, Jirkovska A, Fedjfarova V, Skibová J, Jude EB (2006) Intranasal calcitonin in the treatment of Charcot neuroosteoarthropathy. Diabetes care 29(6): 1392-1394.

31. Khanna D, Arnold EL, Pencharz JN, Grossman JM, Traina SB, et al. (2006) Measuring process of arthritis care: Tthe Arthritis Foundation's quality indicator set for rheumatoid arthritis. Semin Arthritis Rheum 35(4): 211-237.

32. Rogers LC, Frykberg RG, Armstrong DG, Andrew JM Boulton, et al. (2011) The Charcot foot in diabetes. J Am Podiatr Med Assoc 101(5): 437-466.

33. Rogers LC, Bevilacqua NJ, Frykberg RG, Armstrong DG, et al. (2007) Predictors of postoperative complications of Illizarov external ring fixators in the foot and ankle. J Foot Ankle Surg 46(5): 372-375 